\title{
Biogeographic analysis of Crocidiinae (Diptera, Bombyliidae): finding congruence among morphological, molecular, fossil and paleogeographical data
}

\author{
Carlos José Einicker Lamas ${ }^{1,3} \&$ Silvio Shigueo Nihei ${ }^{2}$
}

\begin{abstract}
'Museu de Zoologia, Universidade de São Paulo, Avenida Nazaré, 481, 04263-000 Ipiranga, São Paulo-SP, Brazil. einicker@usp.br ${ }^{2}$ Departamento de Zoologia, Instituto de Biociências, Universidade de São Paulo, Rua do Matão, Travessa 14, n.101, 05508-900 Cidade Universitária, São Paulo-SP, Brazil. silvionihei@gmail.com

${ }^{3}$ Research fellow of Conselho Nacional de Desenvolvimento Científico e tecnológico, CNPq.
\end{abstract}

\begin{abstract}
Biogeographic analysis of Crocidiinae (Diptera, Bombyliidae): finding congruence among morphological, molecular, fossil and paleogeographical data. Biogeographic studies dealing with Bombyliidae are rare in the literature and no information is available on its origin and early diversification. In this study, we found evidence from molecular phylogeny and from fossil record supporting a Middle Jurassic origin of the Bombylioidea, taken as a starting point to discuss the biogeography and diversification of Crocidiinae. Based on a previously published phylogenetic hypothesis, we performed a Brooks Parsimony Analysis (BPA) to discuss the biogeographical history of Crocidiinae lineages. This subfamily is mostly distributed over arid areas of the early components of the Gondwanaland: Chile and southern Africa, but also in southwestern Palaearctic and southwestern Nearctic. The vicariant events affecting the Crocidiinae biogeography at the generic level seems to be related to the sequential separation of a Laurasian clade from a Gondwanan clade followed by the splitting of the latter into smaller components. This also leads to a hypothesis of origin of the Crocidiinae in the Middle Jurassic, the same period in which other bombyliid lineages are supposed to have arisen and irradiated.
\end{abstract}

KEYWORDS. Bee-fly; area cladogram; biogeography; BPA; Gondwanaland.

RESUMO. Análise Biogeográfica de Crocidiinae (Diptera, Bombyliidae): encontrando congruência entre dados morfológicos, moleculares, fósseis e paleogeográficos. Estudos biogeográficos sobre os Bombyliidae são raros na literatura e não há nenhuma informação sobre sua origem e diversificação inicial. Neste estudo encontramos evidências de filogenias moleculares e de registros fósseis suportando a origem dos Bombylioidea no Jurássico Médio. Esse é o nosso ponto de partida para discutir a biogeografia e diversificação de Crocidiinae. A partir de uma hipótese filogenética previamente publicada, realizamos uma Análise de Parcimônia de Brooks (BPA) para discutir a história biogeográfica das linhagens de Crocidiinae. Esta subfamília está distribuída principalmente por áreas áridas dos antigos componentes do supercontinente gondwanico: Chile e Sul da África, além do sudoeste da região Paleártica e sudoeste da região Neártica. Os eventos vicariantes que afetaram a biogeografia de Crocidiinae ao nível genérico parecem ser a separação seqüencial de um clado laurásico e um clado gondwanico, seguido da divisão deste em seus componentes menores. Com base nesses eventos, a origem dos Crocidiinae pode ser inferida para o Jurássico Médio, mesmo período em que outras linhagens de Bombyliidae teriam surgido e irradiado.

PALAVRAS-CHAVE. Cladograma de áreas; biogeografia; BPA; Gondwana.

The Bombyliidae are one of the largest families of Diptera Brachycera with almost 4600 known species (Evenhuis \& Greathead 2003), distributed over all the biogeographic regions of the globe (except for Antarctica and many oceanic islands) (Evenhuis \& Greathead 1999). There are many poorly known taxa, especially in less studied areas such as South America and southern Asia.

The bee flies are most frequently encountered in arid areas and constitute a high percentage of the fly diversity in the more desert regions of the globe (Evenhuis \& Greathead 1999). Adults are commonly seen resting on trails or rocks sunning themselves, or feeding on a variety of flowering plants as they are nectar (males) and obligate nectar and pollen (females) feeders. This feeding behaviour has made them the major pollinators of many flowering plants, especially those occurring in desert regions (Evenhuis \& Greathead 1999).

Bombyliidae is a monophyletic family of flies supported by the following synapomorphies: presence of occipital apodemes; reduced gonocoxal apodemes; ejaculatory apodeme laterally compressed; and presence of a complex sperm pump (Yeates 1994).

Crocidiinae is one of the 15 subfamilies recognized within the family (Evenhuis \& Greathead 1999). As stated by Yeates (1994), its monophyly is based upon two synapomorphies: presence of an apical spur on the mid tibia and the presence of a coxal peg. The phylogenetic relationships of its genera were studied by Lamas \& Couri (2005) (Fig. 1) and their results show that the subfamily is divided into two tribes and eight genera: Desmatomyiini with Desmatomyia Williston, 1895 (3 species) and Inyo Hall \& Evenhuis, 1987 (2 species) and Crocidiini with Apatomyza Wiedemann, 1820 (10 species), Crocidium Loew, 1860 (27 species), Mallophthiria Edwards, 1930 (1 species), Megaphthiria Hall, 1976 (4 species), Semiramis Becker, 1912 (1 species), Timiomyia Evenhuis, 1978 (1 species). 


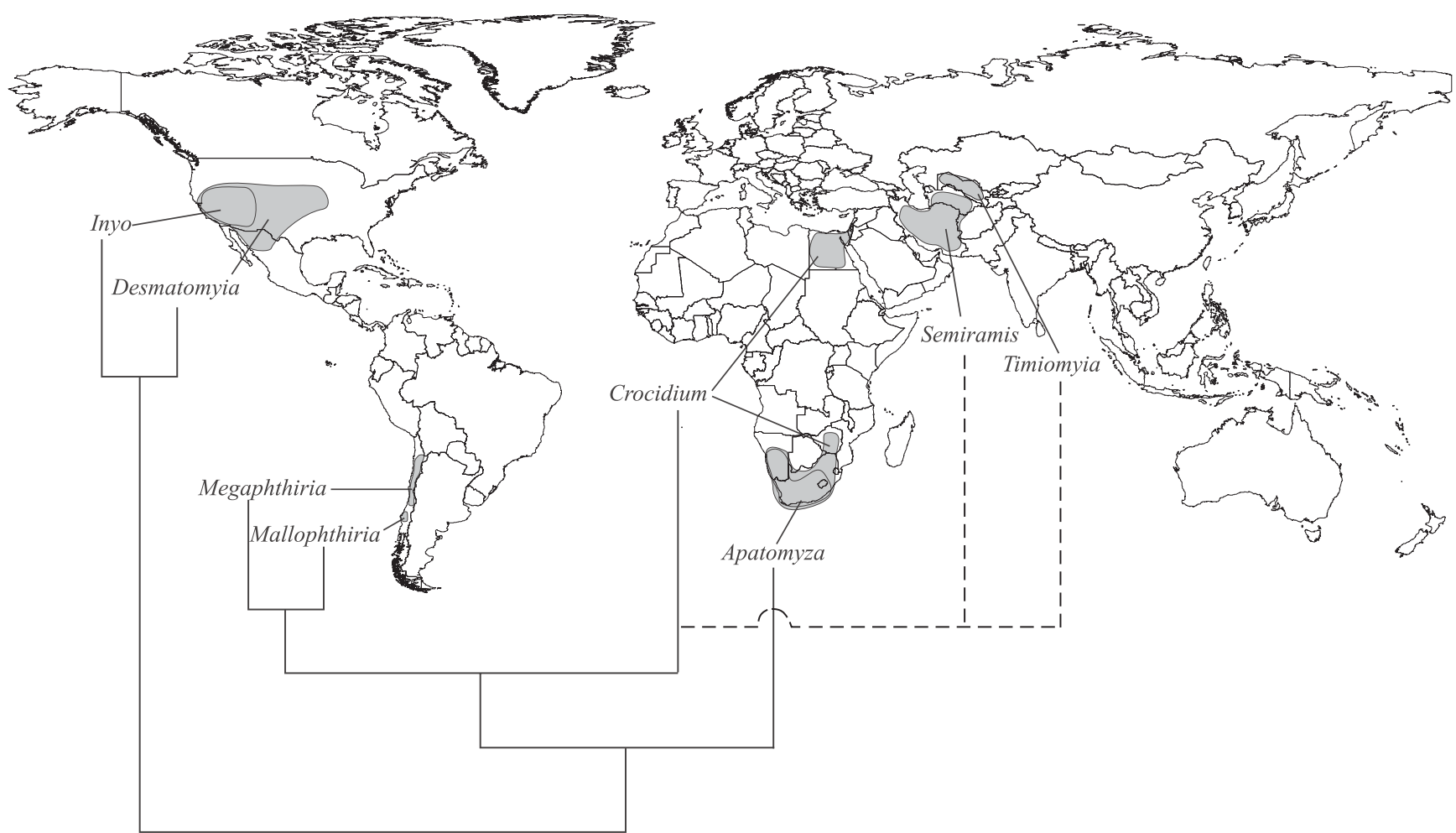

Fig. 1. Geographical distribution and the phylogenetic hypothesis of Crocidiinae genera (dashed lines indicate doubtful relationships; modified from Lamas \& Couri (2005)).

Crocidiinae genera have a remarkably disjunct distribution covering arid areas of the New and Old World (Fig. 1). They are found in the southwestern U.S. (Desmatomyia + Inyo) and Chile (Mallophthiria + Megaphthiria) in the New World, whereas in the Old World they are known from southern Africa (Apatomyza + Crocidium), northern Africa (Crocidium) and south western Asia (Crocidium + Semiramis + Timiomyia).

The major aim of this study is to present a biogeographic analysis of Crocidiinae, reconciling the phylogenetic relationships hypothesized by Lamas \& Couri (2005) for the subfamily with the available data for: 1) distributional pattern; 2) oldest fossil records; 3 ) estimated ages from molecular studies; and 4) paleogeographical events considered to be relevant for the group history. In addition, the discussion is extended to the family and a preliminary biogeographical hypothesis of Bombyliidae is discussed based on the phylogenetic relationships proposed by Yeates (1994).

\section{MATERIALAND METHODS}

For the biogeographical analysis, we performed the Brooks Parsimony Analysis (BPA) (Brooks et al. 2001) aiming to reconstruct the historical relationships among the areas of endemism inhabited by Crocidiinae taxa. Five areas were used: Chile, SW Nearctic, Southern Africa, Northern Africa and SW Asia, as well as an all zero outgroup area to root the trees. The absence/presence of Crocidiinae taxa in these areas was reconciled to its resolved phylogenetic hypothesis (Lamas \& Couri 2005); the resulting data matrix is shown in Table 1. The program NONA version 2.0 (Goloboff 1993) was used for cladogram searching, and WINCLADA (Nixon 2002) for viewing and editing of the tree.

The phylogenetic hypothesis for Crocidiinae (Lamas \& Couri 2005) was modified therein to include the two problematic genera: Semiramis and Timiomyia, polytomic to Crocidium, with which they are probably synonymous (Hull 1973; Lamas $\&$ Couri 2005).

With regard to Bombyliidae, the following modifications were added to the phylogenetic hypothesis of Yeates (1994): Lordotinae sensu Yeates, treated as Bombyliinae sensu Evenhuis \& Greathead (1999); Usiinae sensu Yeates, divided into Usiinae and Phthiriinae sensu Evenhuis (1986) and Evenhuis \& Greathead (1999); Mythicomyiinae sensu Yeates, treated as Mythicomyiidae sensu Zaitzev (1992), Evenhuis (1993), Evenhuis \& Greathead (1999) and Greathead \& Evenhuis (2001); the genus Sericosoma Macquart, 1850 was kept incertae sedis sensu Yeates despite Evenhuis \& Greathead (1999) placing it in Cythereinae; the clade Mythicomyiidae + Bombyliidae is the sister-group to the remaining Heterodactyla following Wiegmann et al. (2003).

Fossil records of Mythicomyiidae and Bombyliidae were gathered from data available mostly in the Catalogue of the fossil flies of the world - web version (Evenhuis 1997, 2002), but also from Evenhuis \& Greathead (1999) and subsequent papers (Poinar \& Poinar 1999; Nel \& Ploëg 2004). Dominican amber from Poinar \& Poinar (1999) was dated following Iturralde-Vinent \& MacPhee (1996).

Biogeographical regions were delimited according to 


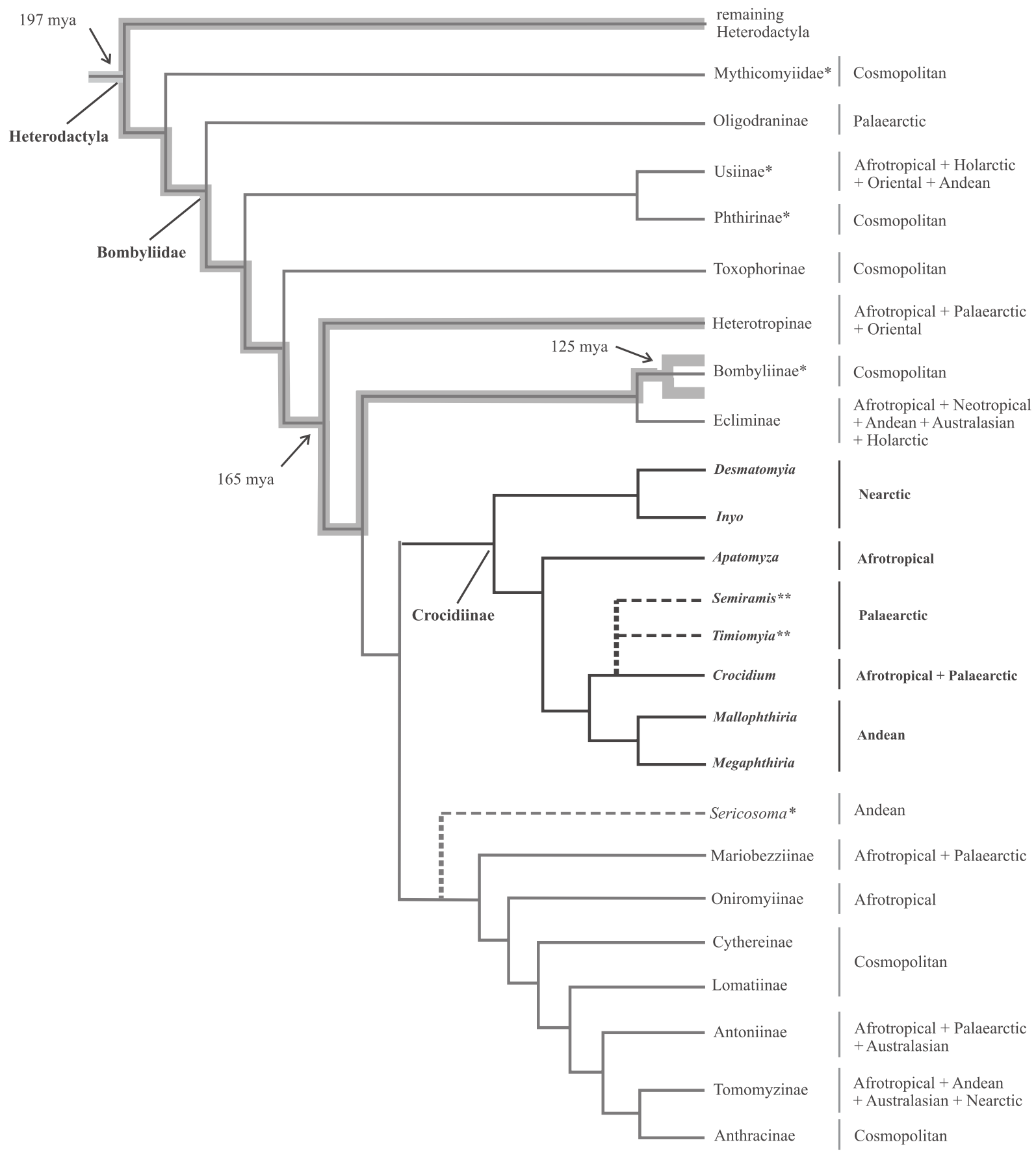

Fig. 2. Phylogenetic relationships among Bombyliidae subfamilies (modified from Yeates (1994)) with emphasis on Crocidiinae genera (in black lines and taxa in black font; modified from Lamas \& Couri (2005)) associated to molecular-based age estimates - mean values (thick light-gray lines; modified from Wiegmann et al. (2003)) and their geographical distribution (at the right side of terminal taxa). Dashed lines indicate doubtful relationships; single asterisks indicate modifications in Yeates (1994) and double asterisks indicate modifications in Lamas \& Couri (2005).

Morrone (2002): Afrotropical, Australian, Nearctic, Neotropical, Oriental, Palaearctic; but the Andean region delimited according to Morrone (2004).

\section{RESULTS ANDDISCUSSION}

There is no study available in the literature discussing the origin and diversification of the Bombyliidae except for some regional analyses and those on lower level taxa (Bowden 1971, 1973, 1974, 1975, 1978; Greathead 2000; and Lambkin et al. 2003). A number of phylogenetic studies have been published at several levels (e.g., Yeates 1989, 1992, 1994; Evenhuis 1990; Zaitzev 1992; Greathead 1995, 1996, 1998, 1999; Lamas \& Couri 1999, 2005; Lambkin et al. 2003), however, none of them treated the studied group on a temporal scale. One of the key concerns for systematists and biologists involved in the Tree of Life 


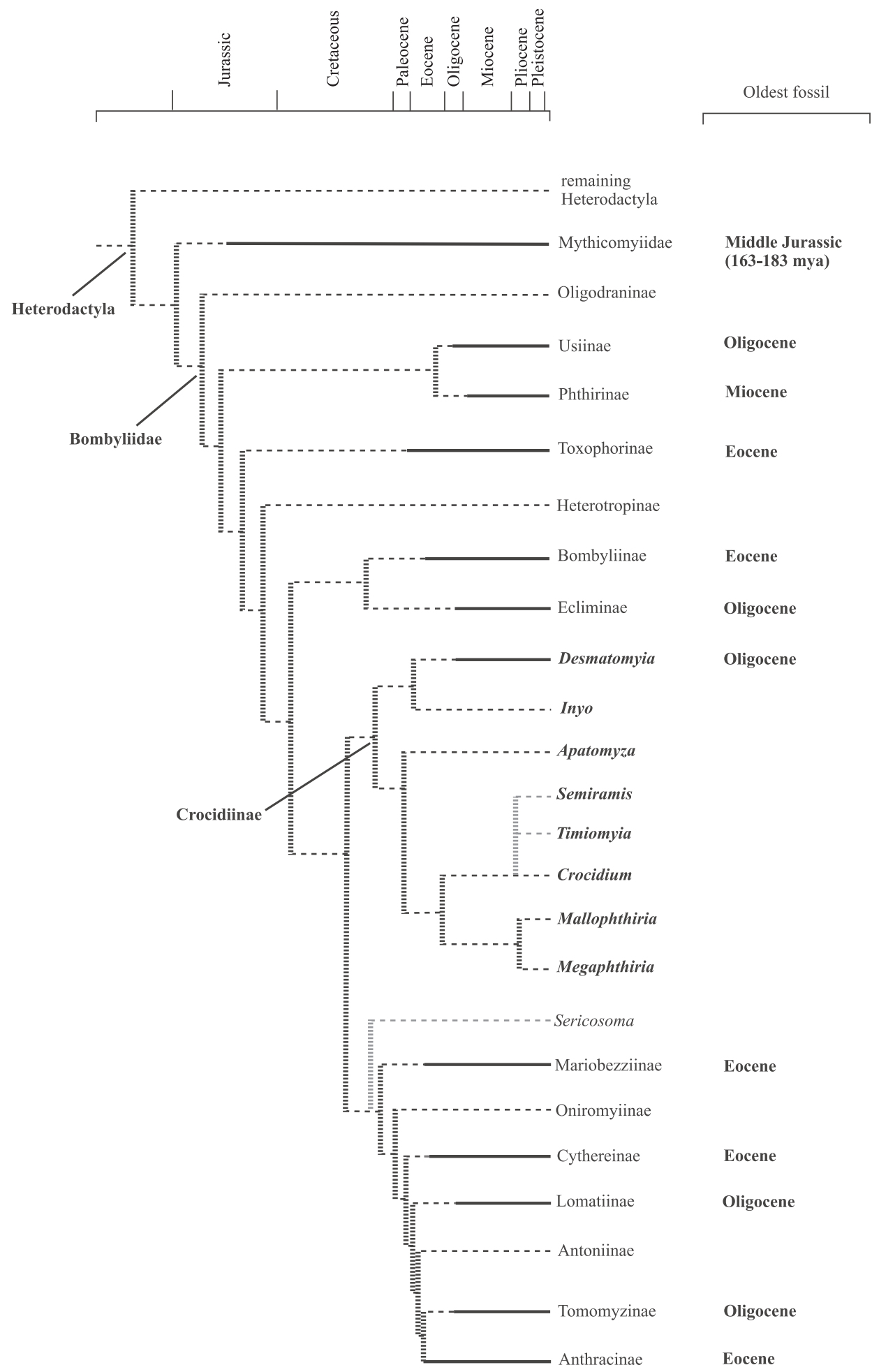

Fig. 3. Phylogenetic relationships among Bombyliidae subfamilies (modified from Yeates (1994)) with emphasis on Crocidiinae genera (in black lines and taxa in black font; modified from Lamas \& Couri (2005)) associated with the oldest fossil record available for Bombyliidae and Mythicomyiidae taxa. Dashed lines indicate nodes or terminal taxa without fossil record; light-gray lines indicate doubtful relationships.

project is the calibration of phylogenies against time, with the source data coming from molecular and paleontological studies (Benton \& Ayala 2003).

Wiegmann et al. (2003) proposed divergence time estimates for the major lineages of brachyceran Diptera by using clock (constant rates of evolution) and non-clock (branch-varying rates of evolution) based calibrations. Although the calibration to Bombyliidae was constrained using minimum clade age of a 


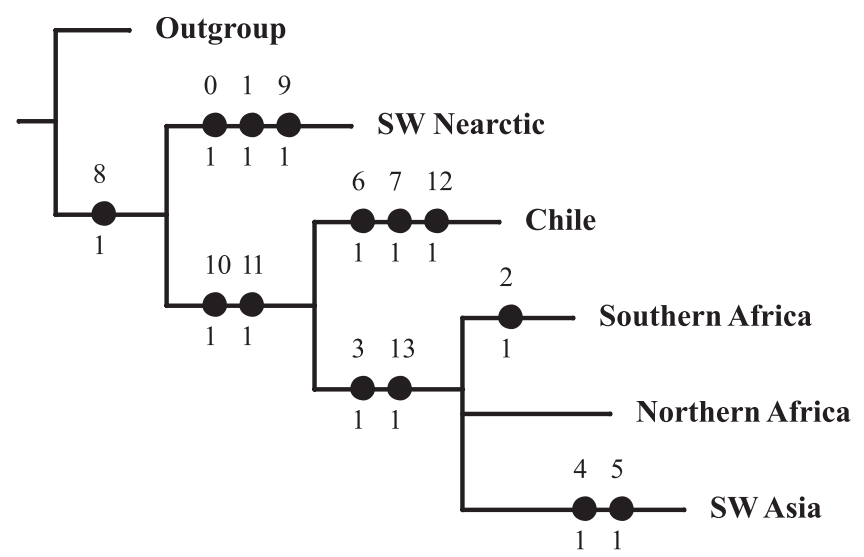

Fig. 4. BPA area cladogram obtained for Crocidiinae.

fossil taxon, currently included among the Mythicomyiidae (Palaeoplatypigus, Siberia; Kalugina \& Kovalev (1985)), the information is still consistent as both families are hypothesized as sister groups and as consequence of the same age. Bombyliidae were aged to $140-190$ Mya (mean $=165$ Mya; see Fig. 2 with the mean values associated with nodes) based on the divergence of Heterotropus (Heterotropinae) from Lordotus+Bombylius (Bombyliinae), and divergence between these two sampled bombyliine taxa was estimated as 90-160 Mya $($ mean $=125$ Mya). Figure 2 depicts the phylogenetic relationships within Bombyliidae associated with geographic distribution and molecular-based ages. Therefore, by considering the mean estimates, the molecular dating procedures age the Bombyliidae lineage back to the Late Jurassic (165 Mya) while the Bombyliinae lineage is aged to the Early Cretaceous (125 Mya). This age is based on divergence between Bombyliinae and Heterotropinae, and perhaps the age of Bombyliidae might be older than the 90-160 Mya estimated by Wiegmann et al. (2003).

Eleven bombyliid subfamilies have fossil records, mostly from the Oligocene (23-35 Mya), but there are also some fossils from the Eocene (35-56 Mya) (Evenhuis 1997; Evenhuis \& Greathead 1999; Poinar \& Poinar 1999; Nel \& Ploëg 2004). Figure 3 presents the oldest fossil records for each of the eleven bombyliid subfamilies and the Mythicomyiidae. The oldest described bombyliid fossils are from Eocene (Fig. 3), but Ren (1998) reported an undetermined putative bombyliid fossil from the Siberian Late Jurassic rocks. This information needs to be confirmed, as the specimen was not examined by any Bombyliidae taxonomist. Furthermore, its hypothesized sister-group, Mythicomyiidae, is recorded from the Middle Jurassic (163-185 Mya), also from Russia (Evenhuis 2002). The Late Jurassic fossil (Ren 1998) is in agreement with the age estimated by molecular studies (discussed above), although the sister-group of Bombyliidae indicates a more ancient age, in the Middle Jurassic. Even so, it is not incongruent with the molecular-based age, as the latter estimated an origin for Bombyliidae ranging from 140 to $190 \mathrm{Mya}$. As Benton \& Ayala (2003) argued, paleontological data are always underestimates, as the oldest fossil must be younger than the origin of its group.

As stated above, there are few studies on bombyliid biogeography, although a few authors made some observations on certain taxa and others on the fauna of certain regions. Evenhuis (1982) suggested that the Comptosiini (Lomatiinae) could have a trans-Antarctic relationship, as it is distributed in South America and Australasia. He considered the Lomatiinae as a true Gondwanan group (Evenhuis, person. comm.). Lambkin et al. (2003) carried out a phylogenetic analysis of the Exoprosopini (Anthracinae) and commented that the basal clade composed of Pseudopenthes (Australia), Atrichochira (Africa, Australia) and Micromitra (Madagascar, Africa, India, Mediterranean) has a Gondwanan distribution. Another exoprosopine genus, Ligyra Newman, 1841 s.l., was considered by Bowden (1971) as a 'true Gondwanan genus'. Ligyra is cosmopolitan in distribution, but predominantly diversified in the Australasian, Afrotropical and Oriental regions, even though Lambkin et al. (2003) transferred the Afrotropical species to the new genus Euligyra). Bowden (1973) considered Dischistus and some related genera to have diversified before late Cretaceous, being also Gondwanan genera. He also stated that the Southern Palaearctic distribution of this group was due to an old Gondwanan stock which invaded Southern Europe and Asia from Africa. Later on, Bowden (1974) associated the mouthparts and body form of Geroninae species as adapted to habits of flower visiting and nectar feeding, suggesting that the subfamily origin could be associated with the Cretaceous expansion of the Angiosperms between late Jurassic and early Cretaceous. On the other hand, Nel \& Ploëg (2004) suggested that the primarily Gondwanan pattern of distribution of Systropodini is not relict but only an artifact of extinction due to climatic changes in the Tertiary.

Most Crocidiinae species seem to have arisen as a result of local speciation, except for the monobasic Chilean Mallophthiria, and the Southwest Asian Semiramis and Timiomyia (Figs 1, 5), which we suggest to be the result of dispersal. Desmatomyia and Inyo are sympatric genera in the Nearctic, and the same occurs with Crocidium and Apatomyza in Southern Africa, but the former seems to have dispersed through North Africa (Egypt) and Middle East (Israel). The two monobasic genera (Semiramis and Timiomyia) from the

Table 1. Data matrix of Crocidiinae for BPA (characters: 0, Desmatomyia; 1, Inyo; 2, Apatomyza; 3, Crocidium; 4, Semiramis; 5, Timiomyia; 6, Mallophthiria; 7, Megaphthiria; 8, Ancestor 1; 9, Ancestor 2; 10, Ancestor 3; 11, Ancestor 4; 12, Ancestor 5; 13, Ancestor 6).

\begin{tabular}{ccccccccccccccc}
\hline Taxa & 0 & 1 & 2 & 3 & 4 & 5 & 6 & 7 & 8 & 9 & 10 & 11 & 12 & 13 \\
\hline Outgroup & 0 & 0 & 0 & 0 & 0 & 0 & 0 & 0 & 0 & 0 & 0 & 0 & 0 & 0 \\
Chile & 0 & 0 & 0 & 0 & 0 & 0 & 1 & 1 & 1 & 0 & 1 & 1 & 1 & 0 \\
Southern Africa & 0 & 0 & 1 & 1 & 0 & 0 & 0 & 0 & 1 & 0 & 1 & 1 & 0 & 1 \\
Northern Africa & 0 & 0 & 0 & 1 & 0 & 0 & 0 & 0 & 1 & 0 & 1 & 1 & 0 & 1 \\
SW Nearctic & 1 & 1 & 0 & 0 & 0 & 0 & 0 & 0 & 1 & 1 & 0 & 0 & 0 & 0 \\
SW Asia & 0 & 0 & 0 & 1 & 1 & 1 & 0 & 0 & 1 & 0 & 1 & 1 & 0 & 1 \\
\hline
\end{tabular}




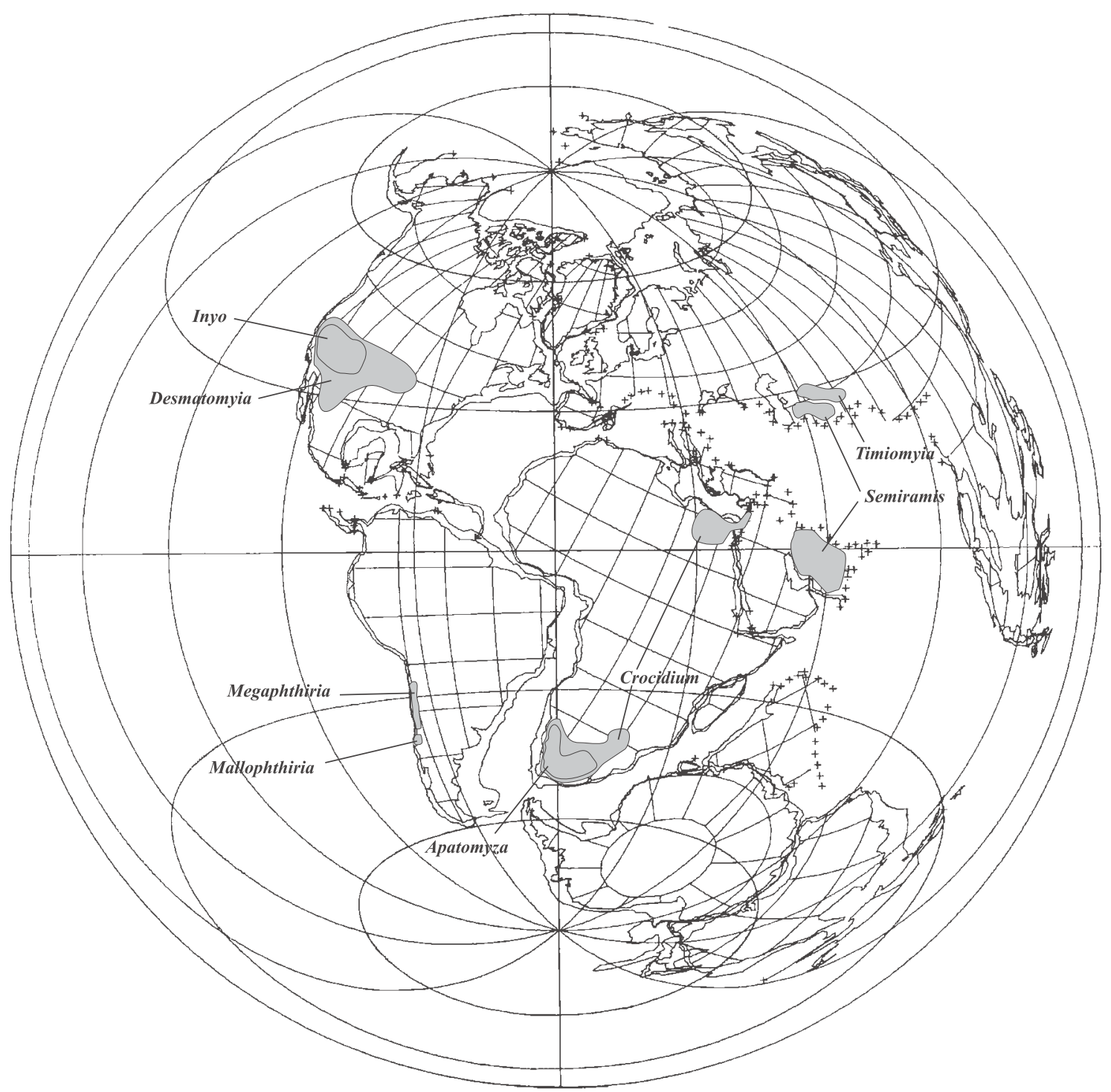

Fig. 5. Geographical distribution of Crocidiinae genera on a paleogeographical map reconstructed for Early Cretaceous, 120 Mya (modified from Smith \& Briden, 1977).

Palaearctic region were not studied since the original descriptions are vague, and their types were not available for this study. As these two genera seem to be similar to Crocidium, Lamas \& Couri (2005) and Hull (1973) suggested that they could be junior synonyms of the latter, which would corroborate the hypothesis of dispersal of the genera northwards.

The BPA cladogram (Fig. 4) depicts the SW Nearctic area as basal to the remaining areas (Chile, S Africa, N Africa and SW Asia). Final separation of the Laurasia from Gondwanaland and its fragmentation into its smaller components occurred from 160-180 Mya in the Middle Jurassic (Sanmartín \& Ronquist 2004). If Crocidiinae diversification is based on vicariance, then the origin of the clade could be dated close to this time. Corroborating this date, there exist a molecular analysis dating the origin of Bombyliidae to 140-190 Mya (Wiegmann et al. 2003), while an undetermined fossil of Bombyliidae is recorded from Late Jurassic (Ren 1998) and a Mythicomyiidae fossil from Middle Jurassic (Evenhuis 2002). Therefore, the most basal event separated the ancestral crocidiine lineage into a Nearctic clade originating Desmatomyia and Inyo from another clade originating the remaining genera. Then, the segregation of the lineage originating Apatomyza in Southern Africa was caused by an ancient unknown event. Later, the lineage Megaphthiria + Mallophthiria in Chile and Crocidium in Africa were separated as the contact of southern South America and Africa was broken from 135 Mya to 106 Mya (Pitman et al. 1993) following the splitting of South America and Africa landmasses. After these vicariant events, what seems to have occurred with Crocidium was the result of speciation within the area followed by dispersal toward the northern portions of Africa.

The exchange of taxa between the deserts of northern and southern Africa was made possible by an arid corridor between 
southwestern Africa and the Horn of Africa during repeatedly drier and colder times, in the Pleistocene and probably also earlier (Koch 1960; Goldblatt 1978; Van Zinderen Bakker 1978; Greathead \& Evenhuis 2001; Beier et al. 2004). As the results of Beier et al. (2004) with the Fagonia genus of desert plant, the Crocidium distribution could thus be explained by dispersal through this corridor and subsequent isolation. Disjunction between the arid zones of northern and southern Africa is also known in many other genera and species (Liston et al. 1989; Thulin 1994; De Winter 1971). As stated by Axelrod \& Raven (1978), savannas attained progressively wider areas as the trend to aridity increased during the Miocene and Pliocene, thus favouring speciation, range spreading and the dispersal to new areas. As a result, the Afrotropical Crocidiinae shows the highest diversification within the subfamily, Apatomyza with 10 species and Crocidium with 27 species (Evenhuis \& Greathead 2003).

If it is possible to correlate the formation of dry corridors crossing Africa along the North-South axis with the northwarddispersal of Crocidium, this would have occurred probably during the Early Miocene (23 Mya), as, after that, the landmass Africa+Middle East collided with Eurasia and completed the union in the Middle Miocene (17-18 Mya), permitting cross dispersion of land animals (Axelrod \& Raven 1978) through the wide connection between Middle East and Eurasia. This could explain the occurrence of crocidiine taxa (Semiramis and Timiomyia) in Eastern Palaearctic areas (Iran, Turkmenistan and Uzbekistan).

Even though the Crocidiinae seem to have Gondwanan origin, they are currently not found in some of the Gondwanaland early components, for example, the Oriental and Australasian regions. However, it would not be surprising, hence, if new collections using Malaise and pan traps in arid areas of these regions detect new crocidiine taxa. These new distributional data would not be incongruent with our biogeographic analysis. Following the geological cladogram of Sanmartín \& Ronquist (2004), the phylogenetic position of an Australasian Crocidiinae in the cladogram of Lamas \& Couri (2005) would be probably adjacent to the Chilean Mallophthiria and Megaphthiria, associated thus with the connection between southern South America, Australia, and Antarctica, which existed until 30-28 Mya (Oligocene) (Sanmartín \& Ronquist 2004).

\section{CONCLUSIONS}

According to our study, the Bombyliidae and its sistergroup, the Mythicomyiidae, probably originated in Middle Jurassic. This statement was corroborated by molecular and fossil data. Hence, the major diversification period within Bombylioidea seems to have occurred during Gondwana (from Late Jurassic). And within the Bombyliidae lineage, the Crocidiinae would have a Gondwanan origin dated to Middle to Late Jurassic, with its present distribution now restricted to arid areas of the globe. Figure 5 shows the present geographical distribution of Crocidiinae over a paleogeographical reconstruction of the Early Cretaceous (120 Mya). This statement, estimating the origin of Crocidiinae to Middle-Late Jurassic, was based on congruence between morphological, molecular, fossil and paleogeographical data. Our study supporting a Gondwanan origin for Crocidiinae is not alone in the bombyliid literature: Lambkin et al. (2003) found a similar Gondwanan pattern for a clade of Exoprosopini within the apical subfamily Anthracinae (sensu Yeates 1994); Bowden (1971, 1973, 1974) considered respectively Ligyra s.l. (Exoprosopini), Dichistus and related genera, and Geroninae as true Gondwanan taxa.

Acknowledgments. Special thanks to Neal Evenhuis (Bishop Museum, Hawaii, USA) and the late David Greathead (Imperial College, London, UK) for valuable comments to an earlier version. Financial support from Fundação de Amparo à Pesquisa do Estado de São Paulo FAPESP (proc. 2004/09431-5 to senior author, and 2004/13663-9 to junior author).

\section{REFERENCES}

Axelrod, D. I. \& P. H. Raven. 1978. Late Cretaceous and tertiary vegetation history of Africa, p. 77-130. In: M. J. A. Werger (ed.). Biogeography and ecology of Southern Africa. Dordrecht. Dr. W. Junk Publishers. 1439 p.

Beier, B. A.; J. A. A. Nylander; M. W. Chase \& M. Thulin. 2004. Phylogenetic relationships and biogeography of the desert plants genus Fagonia (Zygophyllaceae), inferred by parsimony and Bayesian model averaging. Molecular Phylogenetics and Evolution 33: 91-108.

Benton, M. J. \& F. J. Ayala. 2003. Dating the tree of life. Science 300: $1698-1700$.

Bowden, J. 1971. Notes on the genus Ligyra Newman (Diptera: Bombyliidae) with descriptions of three new species from the New Guinea subregion. Journal of the Australian Entomological Society 10: $5-12$.

Bowden, J. 1973. Studies in African Bombyliidae. VII. On Dischistus Loew and related genera, and Bombylisoma Rondani, with some zoogeographical considerations. Journal of the Entomological Society of Southern Africa 36: 139-158.

Bowden, J. 1974. Studies in African Bombyliidae. VIII. On the Geroninae. Journal of the Entomological Society of Southern Africa 37: $87-108$.

Bowden, J. 1975. Studies in African Bombyliidae. IX. On Hyperusia Bezzi and the tribe Corsomyzini. Journal of the Entomological Society of Southern Africa 38: 99-107.

Bowden, J. 1978. 25. Diptera, p. 775-796. In: M. J. A. Werger \& A. C. van Bruggen (eds.). Biogeography and Ecology of Southern Africa. Dordrecht. Dr. W. Junk Publishers. 1439 p.

Brooks, D. R.; M. G. P. Van Veller \& D. A. Mclennan. 2001. How to do BPA, really. Journal of Biogeography 28: 345-358.

De Winter, B. 1971. Floristic relationships between the Northern and Southern arid areas in Africa. Mitteilungen der Botanischen Staatssammlung München 10: 424-437.

Evenhuis, N. L. 1982. Preliminary considerations on the zoogeography of Oceanic Bombyliidae (Diptera: Brachycera). Entomologia Generalis 8: 79-86.

Evenhuis, N. L. 1986. The genera of the Phthiriinae of Australia and the New World (Diptera: Bombyliidae). Honolulu. Privately published. $57 \mathrm{p}$.

Evenhuis, N. L. 1990. Systematics and Evolution of the Genera in the Subfamilies Usiinae and Phthiriinae (Diptera: Bombyliidae) of the world. Entomonograph 11: 1-72.

Evenhuis, N. L. 1993. Catalogue of the types of Southern African Mythicomyiidae (Insecta: Diptera). Genus 4: 91-102. 
Evenhuis, N. L. 1997. Family Bombyliidae. Catalogue of the fossil flies of the world (Insecta: Diptera) - Web Version. Available at the URL: http://hbs.bishopmuseum.org/fossilcat/fossbomb.html (accessed at 15 June 2005).

Evenhuis, N. L. 2002. Family Mythicomyiidae. Catalogue of the fossil flies of the world (Insecta: Diptera) - Web Version. Available at the URL: http://hbs.bishopmuseum.org/fossilcat/ fossmyth.html (accessed at 15 June 2005).

Evenhuis, N. L. \& D. J. Greathead. 1999. World Catalog of Bee Flies (Diptera: Bombyliidae). Leiden. Backhuys Publishers. 756 p.

Evenhuis, N. L. \& D. J. Greathead. 2003. World Catalog of Bee Flies (Diptera: Bombyliidae): Corrigenda and Addenda. Zootaxa 300: 164.

Goldblatt, P. 1978. An analysis of the flora of Southern Africa: its characteristics, relationships, and origins. Annals of the Missouri Botanical Garden 62: 369-436.

Goloboff, P. A. 1993. NONA, version 2.0. Program and documentation distributed by the author.

Greathead, D. J. 1995. A review of the genus Bombylius Linnaeus sensu lato (Diptera: Bombyliidae) from Africa and Eurasia. Entomologica Scandinavica 26: 47-66.

Greathead, D. J. 1996. The genus Bombylisoma Rondani (Diptera: Bombyliidae): phylogenetics and review of species from the Afrotropical region. Entomologica Scandinavica 27: 11-24.

Greathead, D. J. 1998. Review of the Afrotropical and Palaearctic genera of Lomatiinae (Diptera: Bombyliidae). Entomologica Scandinavica 29: 211-222.

Greathead, D. J. 1999. A review of the Afrotropical species of Bombylella Greathead (1995) (Diptera: Bombyliidae). Jounal of Natural History 33: 999-1020.

Greathead, D. J. 2000. The Family Bombyliidae (Diptera) in Namibia, with descriptions of six new species and an annotated checklist. Cimbebasia 16: 55-93.

Greathead, D. J. \& N. L. Evenhuis. 2001. Annotated keys to the genera of African Bombylioidea (Diptera: Bombyliidae; Mythicomyiidae). African Invertebrates 42: 105-224.

Hull, F. M. 1973. The beeflies of the world. The genera of the family Bombyliidae. Bulletin of the United States National Museum 286: 3-687.

Iturralde-Vinent, M. A. \& R. D. E. MacPhee. 1996. Age and paleogeographical origin of Dominican amber. Science 273: 18501852 .

Kalugina, N. S. \& V. G. Kovalev. 1985. Dipterous Insects of Jurassic Siberia. Paleontological Institute, Akademia Nauk, Moscow. 198 p.

Koch, C. 1960. Zweiter taxonomischer Beitrag zur Kenntnis der Tenebrioniden Somalias. Entomologischen Arbeiten aus dem Museum Georg Frey 11: 325-414.

Lamas C. J. E. \& M. S. Couri. 1999. Análise cladística de Euprepina Hull (Diptera, Bombyliidae, Bombyliinae). Revista Brasileira de Zoologia 16: 11-17.

Lamas C. J. E. \& M. S. Couri. 2005. Cladistic analysis of the Crocidiinae (Diptera, Bombyliidae). Studia Dipterologica 11: 513-523.

Lambkin, C. L.; D. K. Yeates \& D. J. Greathead. 2003. An evolutionary radiation of beeflies in semi-arid Australia: systematics of the
Exoprosopini (Diptera: Bombyliidae). Invertebrate Systematics 17: 735-891.

Liston, A.; L. H. Rieseberg \& T. S. Elias. 1989. Genetic similarity is high between intercontinental disjunct species of Senecio (Asteraceae). American Journal of Botany 76: 383-388.

Morrone, J. J. 2002. Biogeograpical regions under track and cladistic scrutiny. Journal of Biogeography 29: 149-152.

Morrone, J. J. 2004. Panbiogeografía, componentes bióticos y zonas de transición. Revista Brasileira de Entomologia 48: 149162 .

Nel, A. \& G. de Ploëg. 2004. New fossil bee flies (Bombylioidea) in the lowermost Eocene amber of the Paris Basin. Geologica Acta 2: $57-65$.

Nixon, K. C. 2002. WINCLADA. Program and documentation distributed by the author.

Pitman, W. C.; S. Cande; J. LaBrecque \& J. Pindell. 1993. Fragmentation of Gondwana: The Separation of Africa from South America, p. 15-34. In: P. Goldblatt (ed.). Biological Relationships between Africa and South America. New Haven. Yale University Press. 360 p.

Poinar, G. \& R. Poinar. 1999. The amber forest. A reconstruction of a vanished world. New Jersey. Princeton University Press. $239 \mathrm{p}$.

Ren, D. 1998. Flower-associated Brachycera flies as fossil evidence for Jurassic angiosperm origins. Science 280: 85-88.

Sanmartín, I. \& F. Ronquist. 2004. Southern Hemisphere Biogeography Inferred by Event-Based Models: Plant versus Animal Patterns. Systematic Biology 53: 216-243.

Smith, A. G. \& J. C. Briden. 1977. Mesozoic and Cenozoic Paleocontinental Maps. Cambridge (UK). Cambridge University Press. 64 p.

Thulin, M. 1994. Aspects of disjunct distributions and endemism in the arid parts of the Horn of Africa, p. 1105-1119. In: J. H. Seyani \& A. C. Chikuni (eds.). Proceedings of the XIIIth meeting AETFAT 2. Zomba. National Herbarium and Botanic Gardens of Malawi. Vol. 2 (p. 795-1514).

Van Zinderen Bakker, E. M. 1978. Quaternary vegetation changes in southern Africa, p. 133-143. In: M. J. A. Werger (ed.). Biogeography and ecology of Southern Africa. Dordrecht. Dr. W. Junk Publishers. 1439 p.

Wiegmann, B. M.; D. K. Yeates; J. L. Thorne \& H. Kishino. 2003. Time flies, a new molecular time-scale for Brachyceran fly evolution without a clock. Systematic Biology 52: 745-756.

Yeates, D. K. 1989. Phylogenetic relationships of the Australian lomatiines (Diptera: Bombyliidae). Systematic Entomology 14: 491-509.

Yeates, D. K. 1992. Towards a monophyletic Bombyliidae (Diptera): the removal of the Proratinae (Diptera: Scenopinidae). American Museum Novittates 3051: 1-30.

Yeates, D. K. 1994. The cladistic and classification of the Bombyliidae (Diptera: Asiloidea). Bulletin of the American Museum of Natural History 219: 1-191.

Zaitzev, V. F. 1992. The phylogeny and system of dipterous insects of the superfamily Bombylioidea (Diptera). Entomologischeskoe Obozrenie 70[1991]: 716-736. [English translation, 1992 in Entomological Review 71: 94-114.]

Received 25/10/2006; accepted 08/05/2007 